AD-A062 452

AIR FORCE GEOPHYSICS LAB HANSCOM AFB MASS SWIRMMUIR ELECTRON FLUORESCENCE MEASUREMENTS IN N2/O2 AND ATR.(U)

F/6 $17 / 5$ UNCLASSTFIED APR 78 B D GREENo 8 E CALEDONIA. R E MURPHY

NL

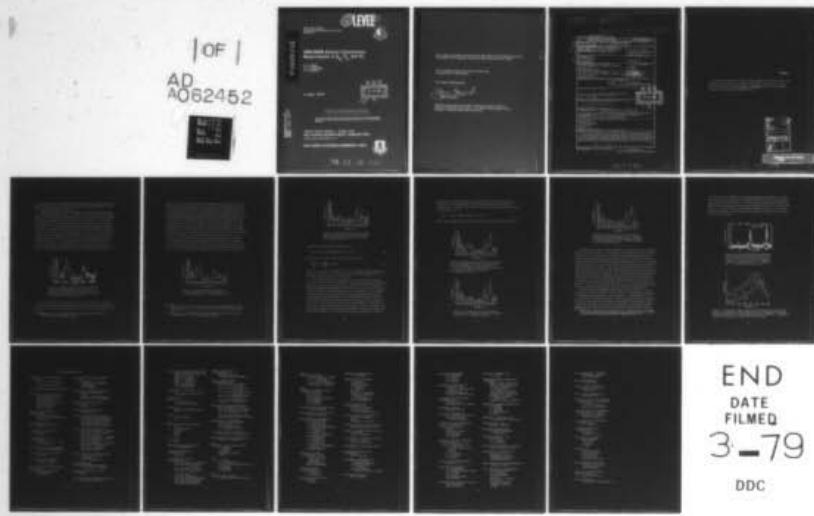

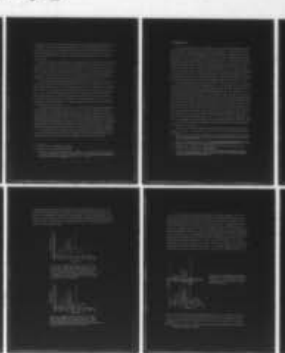

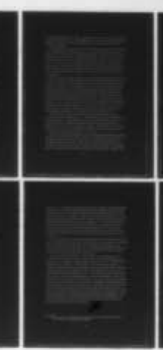

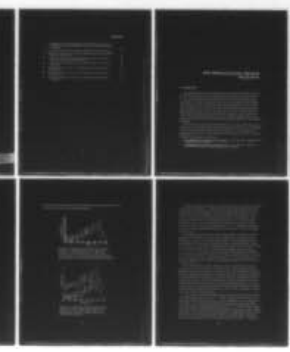

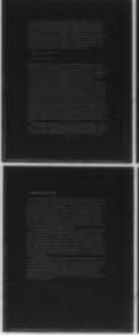

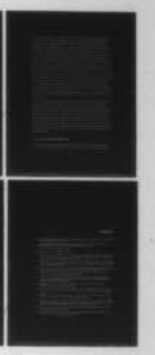

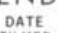

$3-79$

DDC 
AFGL-TR-7 8-0083

\section{(12) LEVEIII}

ENVIRONMENTAL RESEARCH PAPERS, NO. 629

HAES NO. 76

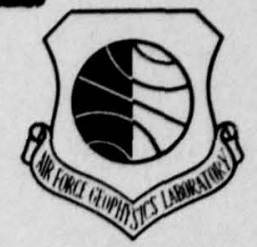

Q

a)

$\nabla 1$

Q

, 6

,

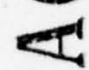

$\mathbb{x}$

4 April 1978
B. D. GREEN
G. E. CALEDONIA
R. E. MURPHY

\section{SWIR-MWIR Electron Fluorescence} Measurements in $\mathrm{N}_{2} / \mathrm{O}_{2}$ and Air

Approved for public release; distribution unlimited.

This research wes sponsored by the Dofense Nuclear Agency under Subtask 125BAXHX632, Work Unit 07, entitled "LABCEDE Investigations of Irradiated $\mathrm{N}_{2}, \mathrm{O}_{2}$ and Other Gaseous Mixtures."

OPTICAL PHYSICS DIVISION PROJECT 2310 AIR FORCE GEOPHYSICS LABORATORY HANSCOM AFB, MASSACHUSETTS 01731

AIR FORCE SYSTEMS COMMAND, USAF

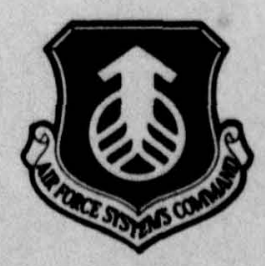

$$
\begin{array}{llll}
78 & 12 & 18 & 158
\end{array}
$$


This report has been reviewed by the ESD Information Office (OI) and is releasable to the National Technical Information Service (NTIS).

This technical report has been reviewed and is approved for publication.

FOR THE COMMANDER

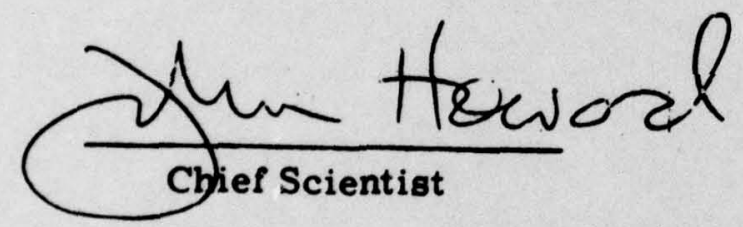

Qualified requestors may obtain additional copies from the Defense Documentation Center. All others should apply to the National Technical Information Service. 


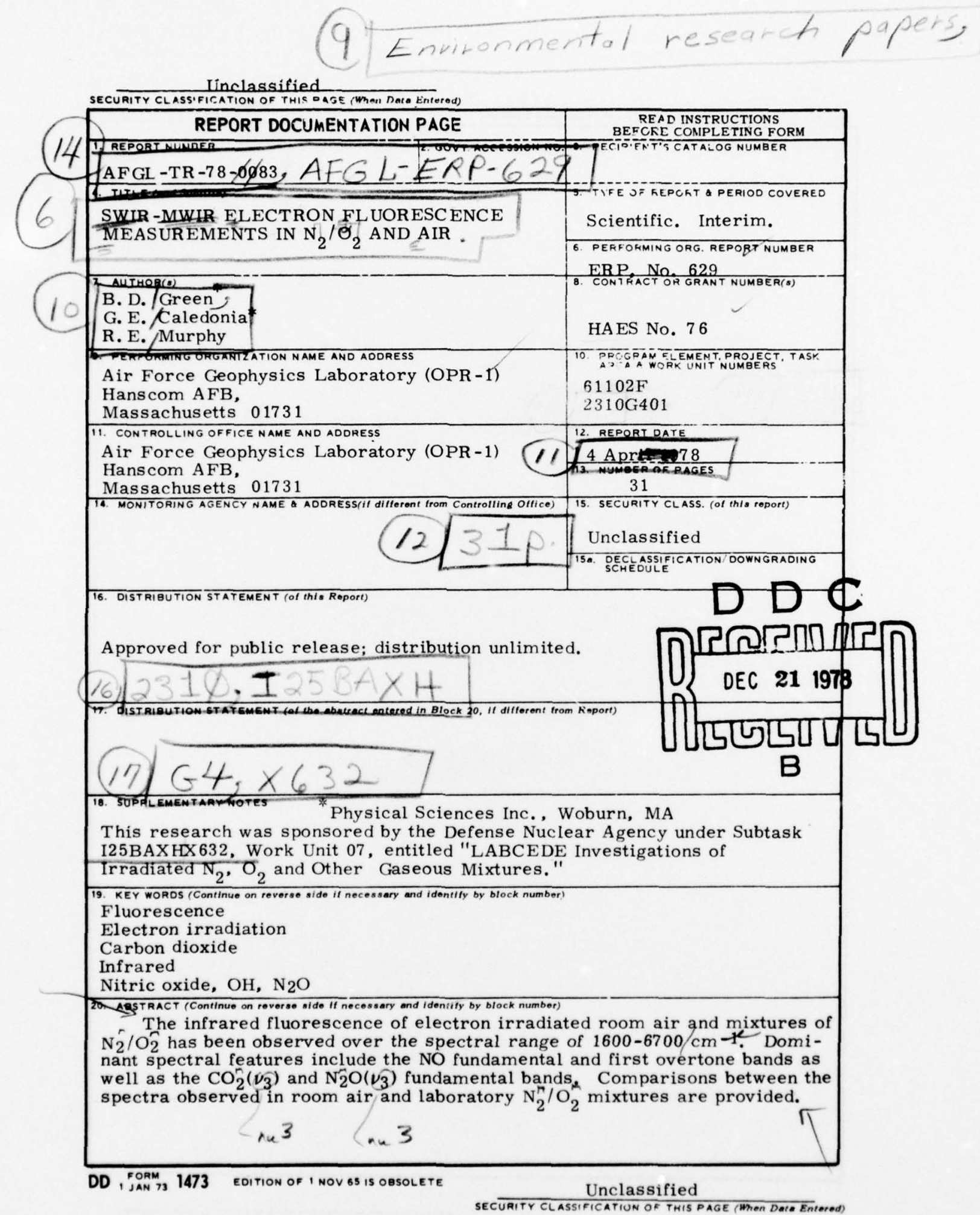




\section{Preface}

The authors would like to thank Dr. Charles Blank for his interest, advice, and support of the work presented. Support by the Defense Nuclear Agency, Atmospheric Effects Division, Subtask S99QAX-H1004-WU07, as part of the LABCEDE Program is acknowledged and appreciated. I

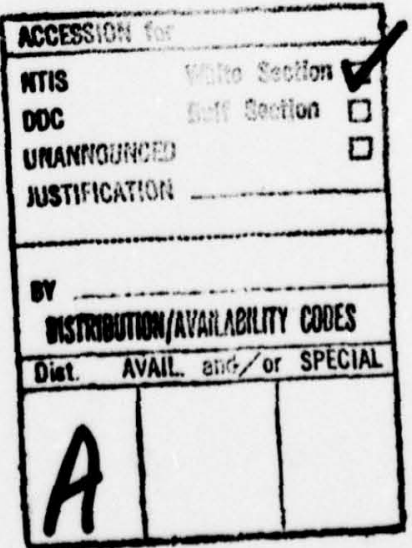




\section{Contents}

1. INTRODUCTION $\quad 7$

2. EXPERIMENTAL 9

3. DATA ANALYSES AND INTERPRETATION 12

4. SUMMARY AND CONCLUSIONS 25

REFERENCES 26

\section{Illustrations}

1. MWIR Fluorescence at Beam Termination From $80 \% \mathrm{~N}_{2} / 20 \% \mathrm{O}_{2}$ Mixtures at 100 Torr Pressure, for Slow-Flow Conditions

2. MWIR Fluorescence of Figure 1 at Beam Termination With $10 \mathrm{~cm}^{-1}$ Resolution

3. MWIR Fluorescence $0.2 \mathrm{msec}$ After Beam Termination for the Same Run as Figure 2

4. MWIR Fluorescence at Beam Termination From Filtered Room Air at 100 Tor: Pressure and Slow-Flow Conditions

5. Fluorescence $0.2 \mathrm{msec}$ After Beam Termination for Conditions of Figure 4

6. Fluorescence at $3.4 \mathrm{msec}$ After Beam Termination for Run of Figures 4 and 5

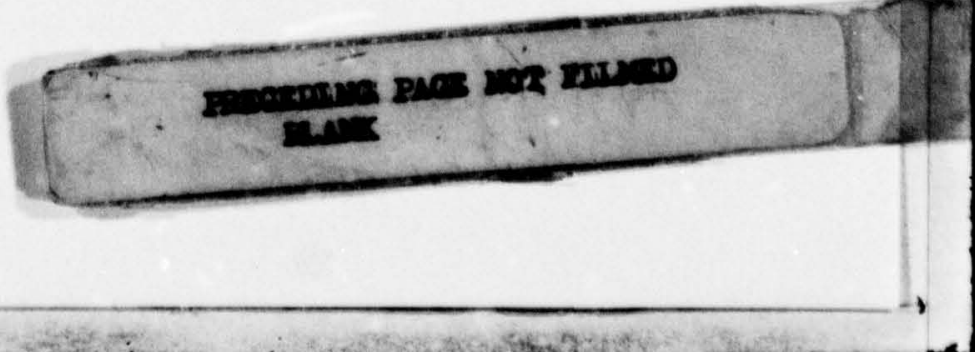




\section{Illustrations}

7. Uncalibrated Fluorescence Observed With $\mathrm{PbS}$ Detector at Beam Termination From Filtered Room Air Under Standard Slow-Flow Conditions

8. Comparison of SWIR Fluorescence with Synthetic Spectrum of NO

9. Spectrum of Filtered Room Air with Estimated $\mathrm{CO}_{2}$ and $\mathrm{N}_{2} \mathrm{O}$ Bands Shown for Comparison

10. SWIR Fluorescence From $80 \% \mathrm{~N}_{2} / 20 \% \mathrm{O}_{2}$ Mixtures at 100 Torr Pressure Under Slow-Flow Conditions

11. Comparison of $\mathrm{N}_{2} / \mathrm{O}_{2}$ and Room Air Spectra Taken Under Similar Conditions

12. SWIR Fluorescence From a Trace Oxygen Run Under Slow-Flow Conditions

13. SWIR Fluorescence $3.5 \mathrm{msec}$ After Beam Termination for Run of Figure 12

14. Comparison of Synthetic Spectrum of OH With Spectral Features of Figure 13 


\section{SWIR - MWIR Electron Fluorescence Measurements in $\mathrm{N}_{2} / \mathrm{O}_{2}$ and Air}

\section{INTRODUCTION}

One of the main topics of discussion at the recent High Altitude Effects Simulation (HAES) Infrared Data Review meeting ${ }^{1}$ was the origin of, and data base for, 2. $7 \mu \mathrm{m}$ band radiation occurring in the quiescent and aurorally disturbed upper atmosphere. The short wave infrared data taken on several recent rocket flights were discussed and some comparisons with theoretical estimates were provided. These predictions were developed under the assumption that the dominant atmospheric radiation source in the $2.7 \mu \mathrm{m}$ region is the NO first overtone vibration/ rotation band. Although this thesis is generally accepted as valid, it has not yet been verified experimentally inasmuch as to date upper atmospheric fluorescence measurements have been performed utilizing radiometers which allow little spectral resolution.

It was pointed out during the meeting ${ }^{2}$ that there are several sets of measurements of $2.7 \mu \mathrm{m}$ radiation which are not consistent with an NO source. Specifically, in some instances measurements of the total columnar $2.7 \mu \mathrm{m}$ radiation as a function of altitude exhibit a behaviour typical of an optically thick source, whereas

(Received for publication 3 April 1978)

1. Proceedings of the HAES Infrared Data Review, 13-15 June 1977, Falmouth, MA, AFGL Report OP-TM-05.

2. Proceedings of the HAES Infrared Data Review, 13-15 June 1977, AFGL Report OP-TM-05, pp 327-341, presented by H. Mitchell. 
atmospheric NO is optically thin. Furthermore it was pointed out that the ratio of 2. $7 \mu \mathrm{m}$ to $5.3 \mu \mathrm{m}$ band radiation observed in recent project EXCEDE measurements ${ }^{3}$ was much too large to be explained in terms of the ratio of the NO first overtone to fundamental band radiation. Lastly, some laboratory measurements of electron irradiated air ${ }^{4}$ were shown to exhibit spectral features due to a species other than NO.

Of course it can be argued that the aforementioned data were either anomalous or affected by contaminants. Indeed the laboratory spectra of Reference 4 was later found to be contaminated by HF that was formed in some complex manner from teflon spacers positioned inside the test chamber. In any event the final resolution of this conflict must await spectrally resolved measurements of the atmospheric radiation. Nonetheless it can be of some interest to define alternate atmospheric sources of $2.7 \mu \mathrm{m}$ radiation that would be consistent with the data base.

Such an analysis has recently been performed ${ }^{2}$ and it was concluded that atmospheric $\mathrm{CO}_{2}$ is the most likely additional source of $2.7 \mu \mathrm{m}$ radiation. It is well known that radiation from the $\mathrm{CO}_{2}$ combination bands $(101 \rightarrow 000)$ and $(021 \rightarrow 000)$ will fall in the $2.7 \mu \mathrm{m}$ region. These transitions are typically ${ }^{5}$ taken to be $1 / 25$ th as weak as the corresponding fundamental band transitions $(101,021 \rightarrow 100,020)$. It was pointed out however that if these transitions were only one fourth as weak as the fundamental transition they could prove to be a significant source of $2.7 \mu \mathrm{m}$ radiation and indeed could provide radiation signatures similar to the anomalous observations discussed above.

The purpose of the present study was to examine, under laboratory conditions, the spectrally resolved fluorescence in the $2.7 \mu \mathrm{m}$ region occurring in electron irradiated air, and to identify the molecular sources of this radiation. This was done utilizing the AFGL/Optical Physics LABCEDE facility which requires total operating pressures greater than 1 Torr. It must be emphasized that this device does not simulate upper atmospheric conditions. Specifically a high degree of collisional quenching will occur in the test chamber and this quenching can obscure radiative phenomena that might be dominant at the lower pressures of the upper atmosphere.

A description of the test facility and the techniques used in taking the fluorescence data is presented in Section 2. The data analysis and interpretation may be found in Section 3 and summary and conclusions are provided in Section 4.

3. O'Neil, R. R., unpublished results.

4. Murphy, R. E., unpublished results.

5. McClatchey, R. A., Benedict, W.S., Clough, S. A., Burch, D. E., Calfee, R. F., Fox, K., Rothman, L.S., and Garing, J. W. (1973) Atmospheric Absorption Line Parameters Compilation, AFCRL-TR-73-0096. 


\section{EXPERIMENTAL}

The LABCEDE facility is a controlled laboratory apparatus designed to study the fluorescence of electron beam irradiated gas mixtures. In this device a constant pressure, continuously flowing gas is irradiated by a collimated, mono-energetic electron beam. The infrared fluorescence from the irradiated gas target is monitored in a plane perpendicular to the excitation beam. This fluorescence may be both spectrally and temporally resolved through the use of a computer interfaced Michelson interferometer. Because of signal-to-noise limitations, the device cannot be operated at gas pressures below approximately 1 Torr and thus cannot be used to provide an exact simulation of processes occurring in the upper atmosphere, for example, $\mathrm{H} \gtrsim 80 \mathrm{~km}$. In the present studies the observation region flow and pressure conditions, as well as beam current and voltage, were chosen to maximize the fluorescence intensity in the short wavelength infrared (SWIR) near 2.7 $\mu \mathrm{m}$.

The LABCEDE apparatus has been described in detail elsewhere, ${ }^{6-9}$ and only an overview of the facility will be presented here. The electron beam is operated in a pulsed mode and in the present study was characterized by a square-wave pulse of $2.5 \mathrm{msec}$ duration and $25 \mathrm{msec}$ period ( $10 \%$ duty cycle). The electrons are accelerated through an adjustable $32-36-\mathrm{kV}$ potential drop, focussed, and sequentially passed through three pinhole nozzles that form a differential pumping network. The differential pumping permits observation chamber operation at pressures of up to 150 Torr while maintaining pressures below $10^{-3}$ Torr in the electron gun. The electron beam current reaching the observation chamber is largely determined by the amount of beam spreading prior to the last pinhole nozzle. The flow and pressure in the observation region directly affect the nozzle chamber pressure due to pump loading, and thus can affect the amount of beam scattering loss for a given run. Typical electron beam currents were $1-2 \mathrm{~mA}$ for $32-36-\mathrm{kV}$ operation. The beam is maintained at approximately constant operating conditions during the course of a run; short term stability fluctuations and long term drift were both less than $5 \%$ of the total current level.

The gases are introduced into the chamber above and to the side of the beam entrance. Mixing of the test gases occurs just outside of the observation chamber.

6. Murphy, R. E., Cook, F. H., Caledonia, G. E. , and Green, B. D. (1977) Infrared Fluorescence of Electron Irradiated $\mathrm{CO}_{2}$ in the Presence of $\mathrm{N}_{2}, \mathrm{Ar}$ and He, AFGL-TR-77-0205.

7. Cook, F.H., and Murphy, R. E. (1976) A Synchronous Signal Processing Technique for Repetitive A rbitrary Waveforms, AFCRL-TR-76-0035.

8. Murphy, R. E., Cook, F.H. , and Sakai, H. (1975) Time resolved Fourier spectroscopy, J. Opt. Soc. Amer. 65:600.

9. O'Neil, R., and Davidson, G. (1968) The Fluorescence of Air and Nitrogen Excited by Energetic Electrons, American Science and Engineering, Inc. report ASE-1602 (AFCRL-67-0277). 
The gas flow rate is measured with a calibrated flowmeter and accurately controlled by knife-edge needle valves. The chamber pressure is monitored by MKS Baratron capacitance manometer with an atmospheric pressure head, referenced to the electron gun pressure.

The fluorescence is monitored by a lead-salt detector mounted at the exit plane of the scanning Michelson interferometer. The moving interferometer mirror, controlled by a voltage ramp, is continuously scanned. Relative mirror movement is monitored by the interference fringes resulting from a helium-neon laser beam positioned parallel to the fluorescent signal. Constructive interference fringes occur every time the mirror changes position by 0.316 microns. The mirror scanning rate is chosen so that on the average 40 beam pulses occur between laser fringes. The detector signal is bandpass amplified (PARC Model 113), interfaced with a Digital PDP-15 computer using an A/D converter, processed, and stored on magnetic tape.

Observation of the temporal dependence of the fluorescence spectrum is made possible by a sample and hold network referenced to the electron beam pulse onset. ${ }^{8}$ The network output is directly input into the $A / \mathrm{D}$ converter, at sampled intervals less than the detection system response time. The A/D converter time resolution limitation is around $40 \mu \mathrm{sec}$, and for these experiments, the resolution limit is determined by the detector and amplification network. Because of the detector limitations it was not possible to measure the emission of the NO fundamental and first overtone vibration/rotation bands simultaneously. A PbSe detector, cooled to $77^{\circ} \mathrm{K}$, was used to monitor fluorescence in the mid-wavelength infrared region (MWIR) near $5 \mu \mathrm{m}$. This detector had a $75 \mu$ sec response time which was degraded to $200 \mu \mathrm{sec}$ by the bandpass amplifier in order to decrease the noise level. A PbSe detector (at $195^{\circ} \mathrm{K}$ ) was used for the SWIR measurements. This detector exhibits higher responsivity but is limited to a $2 \mathrm{msec}$ response time.

Averaging of the appropriate detector intensities between laser fringes is performed to increase signal-to-noise. These averaged signals are then stored on magnetic tape as a single point in each of the time resolved interferograms. For all the experiments sufficient data points (at different mirror positions) were gathered to provide for $10 \mathrm{~cm}^{-1}$ spectral resolution. Degradation of the resolution to artificially decrease the apparent noise level could then be performed mathematically by the computer at a later time if desired.

The gases used in these experiments were ultrahigh purity nitrogen and oxygen, and room air. When use was made of room air, it was introduced into the chamber through the flowmeter and needle valve in order to match the cylinder gas flow conditions as closely as possible. The room air could be filtered to remove dust and water vapor by means of a glass wool/silica gel desiccant trap. This trapping system was found to be effective in removing water vapor from the laboratory air. 
The infrared fluorescence intensity was found to be optimized at relatively slow conditions, 2.5 standard liters per min total flow, with pumping of the test chamber occurring only through the electron beam differential pumping system. The optimized chamber operating pressure was 100 Torr and the residence time of the test gas was 30 seconds. Under these flow conditions beam created species are likely to build up in the observation region. Specifically nitrogen and oxygen atoms are produced in the test gas either by direct electron impact dissociations or by subsequent electron/ion/neutral reactions. These atoms can then produce other chemical species such as $\mathrm{NO}, \mathrm{O}_{3}, \mathrm{NO}_{2}, \mathrm{~N}_{2} \mathrm{O}$. The present experiments are designed to study NO fluorescence resulting from the reactions

$$
\begin{aligned}
& \mathrm{N}\left({ }^{4} \mathrm{~S}\right)+\mathrm{O}_{2} \rightarrow \mathrm{NO}(\mathrm{v})+\mathrm{O} \\
& \mathrm{N}\left({ }^{2} \mathrm{D}\right)+\mathrm{O}_{2} \rightarrow \mathrm{NO}(\mathrm{v})+\mathrm{O}
\end{aligned}
$$

If the gas residence time is long compared to the beam pulsing time the amount of $\mathrm{NO}$ and other beam created species will increase pulse by pulse until reaching a steady state level. The details of the relevant chemical kinetics for $\mathrm{N}_{2} / \mathrm{O}_{2}$ mixtures may be found in Reference 6 . It is not anticipated that the presence of these beam created species will affect the conclusions of this study however, their presence must be considered when interpreting the experimental observations.

Attempts to decrease the gas residence time result in a loss of fluorescent intensity. Increasing the flow and pumping rates at constant chamber pressure leads to beam current degradation; pressure reduction at constant flow causes a reduction in the total energy deposition of the beam within the field-of-view. As a result, only slow flow measurements were made in the MWIR region. On the other hand, because of the greater sensitivity of the PbS detector, SWIR fluorescence measurements could be made both at the slow flow conditions and also at flow rates of 5 standard liters per minute. For these latter flow rates, and a chamber pressure of 12 Torr, the beam current degradation may be kept at an acceptable level, while the gas chamber residence time is decreased to 2 seconds. Consequently, in these measurements the build-up of beam created species is greatly reduced. Experiments performed in the past ${ }^{6}$ with an integrating sphere in the chamber have resulted in increased signal level at the expense of the residence time and field-of-view definition. No attempt was made to implement the integrating sphere in the present study.

Experimental measurements were first made in the MWIR region in order to observe the temporal behavior of the NO fundamental band radiation $(\Delta v=1)$ with $0.2 \mathrm{msec}$ resolution. Additionally, the presence and relative strengths of radiation from $\mathrm{CO}_{2}\left(\nu_{3}\right)$ and $\mathrm{N}_{2} \mathrm{O}\left(\nu_{3}\right)$ transitions at $4.3 \mu \mathrm{m}$ and $4.5 \mu \mathrm{m}$ could be examined. 
A series of slow flow runs using first, a mixture of $80 \% \mathrm{~N}_{2} / 20 \% \mathrm{O}_{2}$, then trapped (dried) room air, and finally unfiltered room air, were made keeping chamber pressure, beam current, and voltage constant at 100 Torr, $1.6 \mathrm{~mA}$, and $36 \mathrm{kV}$ respectively. When unfiltered air was used, no significant detector signal could be obtained. It is expected that the level of fluorescence in this case is diminished because of the efficient quenching of vibrationally excited states by water vapor.

A similar series of measurements was made in the SWIR, NO overtone, spectral region with the PbS detector. The experimental conditions of the MWIR measurements were duplicated as much as possible. Beam currents achieved were slightly different, $1.2 \mathrm{~mA}-1.8 \mathrm{~mA}$, but all other parameters were unchanged. Because of the increased sensitivity of this detector, signal was observed even for the case of unfiltered air. Fast flow measurements were made with both cylinder gases and filtered room air at $36 \mathrm{kV}$, but at a reduced beam current of $0.9-1.4 \mathrm{~mA}$. Although the magnitude of the beam current was decreased in these runs, the current stability was maintained at the $5 \%$ fluctuation level. The total fluorescence intensity for these cases was reduced by more than a factor of 2 below that of the slow flow cases.

An additional set of measurements at reduced oxygen partial pressures was made both in the MWIR and SWIR regions. At the same total pressure, it was found that mixtures with fractional oxygen concentrations of $1-3 \times 10^{-4}$ of the nitrogen pressure provided the maximum NO fluorescence intensity. The total fluorescence intensity of these runs was a factor of 4 larger than those observed in the air mixtures.

The final collected data base included 8 runs taken with the PbSe detector and 15 runs taken with the PbS detector. In several instances measurements were repeated over a period of several weeks in order to ensure data reproducibility. Furthermore detector spectral response calibrations were performed daily using a black body radiation source. The collected experimental data (stored on magnetic tape) was processed by first sorting the data into time-resolved interferograms, Fourier transforming them into spectra, then applying a correction for detector spectral response and field-of-view. The final form of the reduced data is a series of time-resolved, calibrated spectra for each run. Spectral resolution, up to the maximum of $10 \mathrm{~cm}^{-1}$, is determined by the number of interferogram points included in the transformation. These spectra are then used for species identification and kinetic analysis.

\section{DATA ANALYSIS AND INTERPRETATION}

The signal-to-noise ratio of the data taken in the MWIR was sufficiently low so that the observed spectra exhibited a "spikey" structure. The apparent noise 
level could be diminished by artificially degrading the spectral resolution to $20 \mathrm{~cm}^{-1}$; however, this had to be done with care inasmuch as real spectral features can be inadvertantly washed out by this procedure.

A typical MWIR spectra, taken in a mixture of $80 \% \mathrm{~N}_{2} / 20 \% \mathrm{O}_{2}$ at a total pressure of 100 Torr, is shown in Figure 1. This data was taken with the PbSe detector under slow flow conditions and corresponds to a time just prior to beam termination; the spectral resolution of the data has been degraded to $20 \mathrm{~cm}^{-1}$. Two distinct spectral features are apparent. The first of these, spanning the spectral range of $1760-1925 \mathrm{~cm}^{-1}$, is the result of NO fundamental vibrational/rotational band fluorescence, arising from NO molecules with up to 6 quanta of vibrational excitation. Radiation from the $\mathrm{N}_{2} \mathrm{O}\left(\nu_{3}\right)$ band is also observed at $2223 \mathrm{~cm}^{-1}$. Note that neither of these species is present in the original test gas and thus both must be created through chemical reactions such as (1) and (2). From a knowledge of the relevant Einstein coefficients, ${ }^{5,10}$ it can be determined that the populations of the vibrationally excited $\mathrm{NO}$ and $\mathrm{N}_{2} \mathrm{O}$ responsible for the fluorescence are in the ratio of 7 to 1 . No other significant spectral radiators are observed in the bandpass of this detector. (The feature at $1630 \mathrm{~cm}^{-1}$ is an artifact of the spectral calibration.)

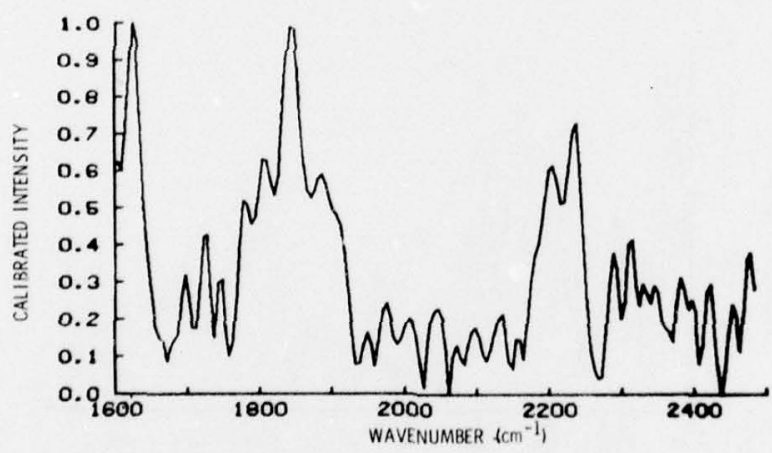

Figure 1. MWIR Fluorescence at Beam Termination From $80 \% \mathrm{~N}_{2} / 20 \% \mathrm{O}_{2}$ Mixtures at 100 Torr Pressure, for Slow-Flow Conditions. Resolution is $20 \mathrm{~cm}^{-1}$. Electron beam current was $1.6 \mathrm{~mA}$, voltage was $36 \mathrm{kV}$. $\mathrm{NO}$ and $\mathrm{N}_{2} \mathrm{O}\left(\nu_{3}\right)$ radiation are evident

The same spectrum is shown in Figure 2 at $10 \mathrm{~cm}^{-1}$ resolution. The large noise level is due to the combination of poor detector response and low fluorescence levels. It can be seen, however, that the basic spectral features of Figures 1 and 2

10. Billingsley, II, F.P. (1976) Calculated vibration rotation intensities for $\mathrm{NO}\left(\mathrm{X}^{2} \mathrm{II}\right)$, J. Molec. Spectrosc. $61: 53$. 
are the same. The spectrum of Figure 3 corresponds to the same case at a time of $0.2 \mathrm{msec}$ after beam termination. The time difference between Figures 2 and 3 is equal to the response time of the detection network. The intensity scale is the same for both figures and it can be seen that with increased time the fluorescence due to $\mathrm{NO}$ is greatly diminished, while the $\mathrm{N}_{2} \mathrm{O}$ signal is essentially unchanged. The rate constants for vibrational quenching of $\mathrm{NO}(\mathrm{v}=1)$ by $\mathrm{N}_{2}$ and $\mathrm{O}_{2}$ have been measured ${ }^{11}$ as $1.7 \times 10^{-16} \mathrm{~cm}^{3} / \mathrm{sec}$ and $2.4 \times 10^{-14} \mathrm{~cm}^{3} / \mathrm{sec}$ respectively leading to a predicted NO fluorescence decay time of $0.07 \mathrm{msec}$ for the present case. The observed NO decay is limited by the time resolution of the experiment. $\mathrm{N}_{2} \mathrm{O}\left(\nu_{3}\right)$ quenching by $\mathrm{N}_{2}$ has been measured ${ }^{12}$ to have a rate constant of $4 \times 10^{-15} \mathrm{~cm}^{3} / \mathrm{sec}$, and thus the $\mathrm{N}_{2} \mathrm{O}\left(\nu_{3}\right)$ fluorescence would be expected to decay on the same time scale, as NO, $10^{-4}$ seconds. The $\mathrm{N}_{2} \mathrm{O}$ fluorescence in this experiment is observed to decay with a time constant of $20 \mathrm{msec}$, thus implying the presence of a source of $\mathrm{N}_{2} \mathrm{O}$ vibrational excitation in the test gas after beam termination. Vibrationally excited molecular nitrogen (that is, excited by beam electrons) is a known energy reservoir under these conditions ${ }^{6}$ and near-resonance vibrational exchange between $\mathrm{N}_{2} \mathrm{O}\left(\nu_{3}\right)$ and $\mathrm{N}_{2}(\mathrm{v})$ is postulated as an explanation for the observed slow $\mathrm{N}_{2} \mathrm{O}$ decay.

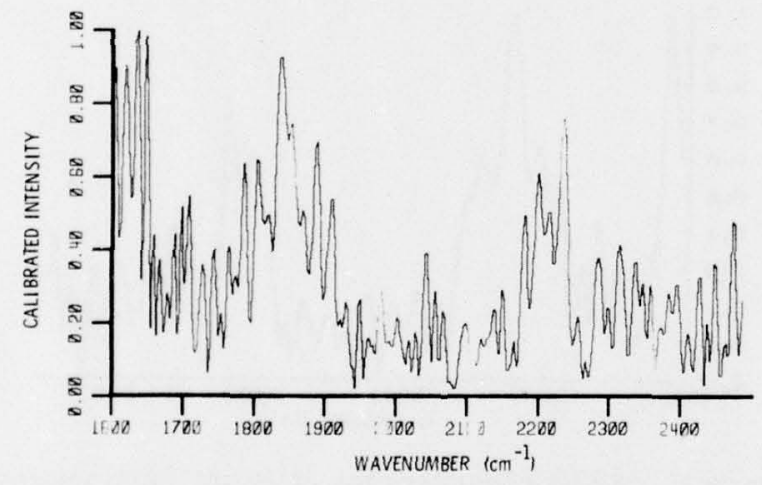

Figure 2. MWIR Fluorescence of Figure 1 at Beam Termination With $10 \mathrm{~cm}^{-1}$ Resolution. Normalized to $I_{\max }=6.9 \times 10^{-9} \mathrm{~W} / \mathrm{cm}^{2}-\mathrm{str}-\mathrm{cm}^{-1}$

11. Murphy, R. E., Lee, E. T.P. , and Hart, A. M. (1975) Quenching of vibrationally excited nitric oxide by molecular oxygen and nitrogen, J. Chem. Phys. 63: 2919 .

12. Yardley, J.T. (1968) Vibration-to-vibration energy transfer in gas mixtures containing nitrous oxide, J. Chem. Phys. $49 \dot{w}^{2816 .}$ 


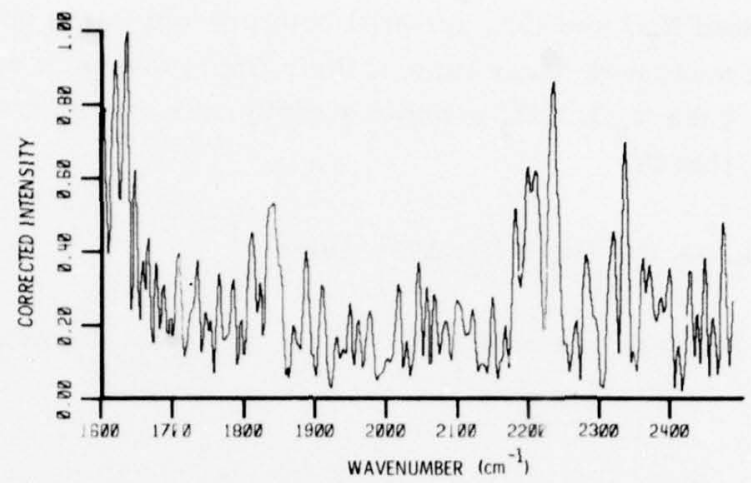

Figure 3. MWIR Fluorescence $0.2 \mathrm{msec}$ After Beam Termination for the Same Run as Figure 2. Resolution is $10 \mathrm{gm}^{-1}$. Maximum intensity is $6.9 \times 10^{-9} \mathrm{~W} / \mathrm{cm}^{2}-\mathrm{str}-\mathrm{cm}^{-1}$

Specifically, the vibrational exchange reaction

$$
\mathrm{N}_{2}(\mathrm{v}=1)+\mathrm{N}_{2} \mathrm{O} \leftrightarrow \mathrm{N}_{2} \mathrm{O}\left(\nu_{3}\right)+\mathrm{N}_{2} ; \Delta \mathrm{E}=137 \mathrm{~cm}^{-1}
$$

is assumed to be in local steady state so that to first order

$$
\frac{\mathrm{N}_{2}(\mathrm{v}=1)}{\mathrm{N}_{2}}=\frac{\mathrm{N}_{2} \mathrm{O}\left(\nu_{3}\right)}{\mathrm{N}_{2} \mathrm{O}} \mathrm{e}^{-\Delta \mathrm{E} / \mathrm{kT}}
$$

and thus, since $\mathrm{N}_{2} \mathrm{O}$ is a trace species, the decay of $\mathrm{N}_{2} \mathrm{O}\left(\nu_{3}\right)$ mirrors the decay of vibrationally excited $\mathrm{N}_{2}$. The large energy defect between $\mathrm{N}_{2}$ and $\mathrm{NO}, 484 \mathrm{~cm}^{-1}$, precludes a similar effect in the case of NO.

In Figure 4 the spectrum of irradiated filtered room air under slow-flow conditions is displayed at beam termination. Both $\mathrm{NO}$ and $\mathrm{N}_{2} \mathrm{O}\left(\nu_{3}\right)$ fluorescence are observed along with radiation from $\mathrm{CO}_{2}\left(\nu_{3}\right)$ at $2350 \mathrm{~cm}^{-1}(4.3 \mu \mathrm{m})$ as expected. The $\mathrm{N}_{2} \mathrm{O}\left(\nu_{3}\right)$ fluorescence intensity is increased by $20 \%$ over that of the $\mathrm{N}_{2} / \mathrm{O}_{2}$ runs of Figures 2 and 3, while the NO fluorescence has decreased by a third. Carbon dioxide is the dominant spectral radiator. From consideration of the relative bandstrengths of $\mathrm{CO}_{2}, \mathrm{~N}_{2} \mathrm{O}$, and $\mathrm{NO}$, it may be estimated that the $\mathrm{N}_{2} \mathrm{O}\left(\nu_{3}\right)$ and $\mathrm{NO}(\mathrm{v})$ concentrations at beam termination relative to that of $\mathrm{CO}_{2}\left(\nu_{3}\right)$ are 1.4 and 5.6 to 1 respectively. A spectrum from the same case corresponding to the fluorescence $0.2 \mathrm{msec}$ after beam termination is shown in Figure 5. Again the NO fluorescence has disappeared while both the $\mathrm{N}_{2} \mathrm{O}$ and $\mathrm{CO}_{2}$ fluorescence remain unchanged. The fluorescence detected $3.4 \mathrm{msec}$ after beam termination is displayed in Figure 6 . 
Vibrationally excited $\mathrm{N}_{2} \mathrm{O}$ and $\mathrm{CO}_{2}$ are still both present in the same relative concentrations. The measure decay time of their fluorescence is approximately 14 milliseconds. Like $\mathrm{N}_{2} \mathrm{O}, \mathrm{CO}_{2}$ exhibits a rapid near resonant vibrational exchange reaction with $\mathrm{N}_{2}$, that is,

$$
\mathrm{N}_{2}(\mathrm{v}=1)+\mathrm{CO}_{2} \leftrightarrow \mathrm{CO}_{2}\left(\nu_{3}\right)+\mathrm{N}_{2} ; \Delta \mathrm{E}=19 \mathrm{~cm}^{-1}
$$

and thus the $\mathrm{CO}_{2}$ fluorescence will also mirror the decay of vibrationally excited $\mathrm{N}_{2}$.

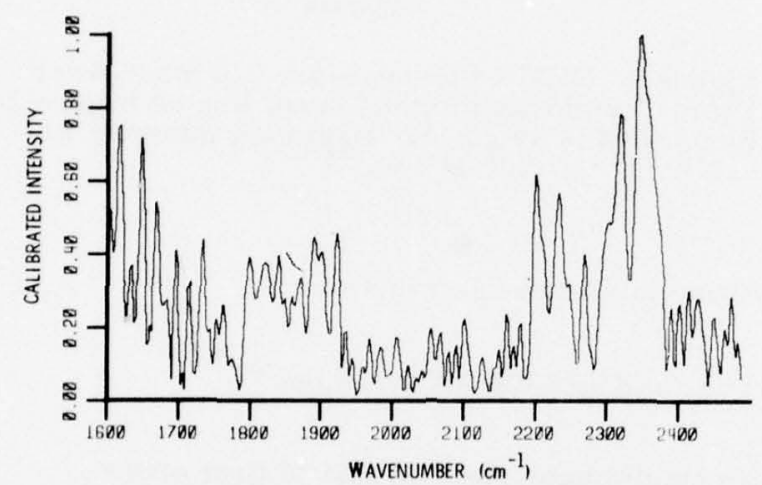

Figure 4. MWIR Fluorescence at Beam Termination From Filtered Room Air at 100 Torr Pressure and Slow -Flow Conditions. Resolution is $10 \mathrm{~cm}^{-1}$, $\mathrm{i}=1.6 \mathrm{~mA}$. Radiation from NO, $\mathrm{N}_{2} \mathrm{O}\left(\nu_{3}\right)$ and $\mathrm{CO}_{2}\left(\nu_{3}\right)$ can be observed. Maximum intensity is

$1.1 \times 10^{-8} \mathrm{~W} / \mathrm{cm}^{2}-\mathrm{str}-\mathrm{cm}^{-1}$

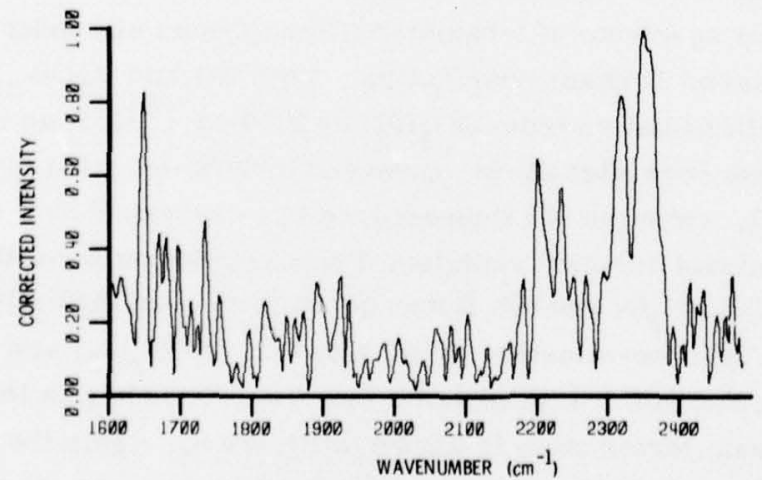

Figure 5. Fluorescence $0.2 \mathrm{msec}$ After Beam Termination for Conditions of Figure 4. Maximum intensity is $1.1 \times 10^{-8} \mathrm{~W} / \mathrm{cm}^{2}-\mathrm{str}-\mathrm{cm}^{-1}$ 


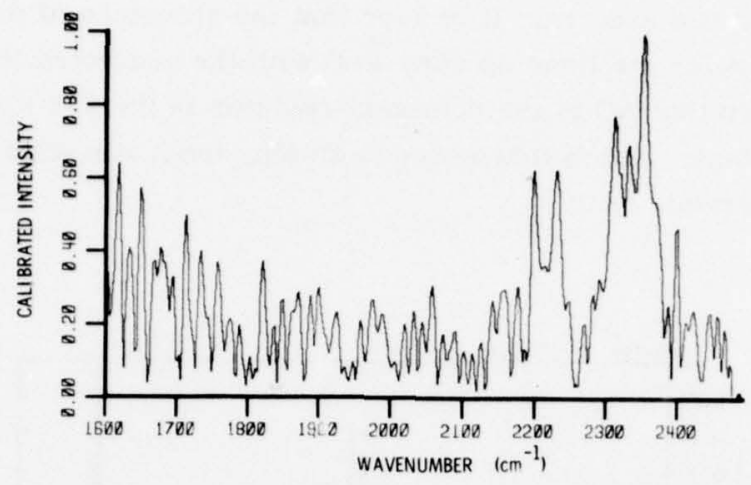

Figure 6. Fluorescence at $3.4 \mathrm{msec}$ After Beam Termination for Run of Figures 4 and $5 . \mathrm{CO}_{2}\left(\nu_{3}\right)$ and $\mathrm{N}_{2} \mathrm{O}\left(\nu_{3}\right)$ Radiation are only slightly diminished from beam termination values. Maximum intensity is $9.1 \times 10^{-9} \mathrm{~W} / \mathrm{cm}^{2}-\mathrm{str}-\mathrm{cm}^{-1}$

A spectrum taken under slow-flow conditions in filtered room air using the $\mathrm{PbS}$ detector is shown in Figure 7. This spectrum, corresponding to the time of beam termination, has a resolution of $20 \mathrm{~cm}^{-1}$ and is uncorrected for the spectral response of the detector; the $\mathrm{CO}_{2}\left(\nu_{3}\right)$ radiation at $2350 \mathrm{~cm}^{-1}$ is by far the strongest feature observed although this detector is relatively insensitive to $4.3 \mathrm{um}$ radiation. $\mathrm{N}_{2} \mathrm{O}\left(\nu_{3}\right)$ fluorescence, not a prominent feature in the spectrum shown, has also been observed with the $\mathrm{PbS}$ detector. The calibrated intensity of the $\mathrm{CO}_{2}\left(\nu_{3}\right)$ radiation shown in Figure 7 agrees to within $20 \%$ with a value obtained using the PbSe detector under similar experimental conditions. This excellent agreement reflects both the accuracies of the detector calibrations and the good run-to-run reproducibility of the data base. The other spectral features evident in Figure 7 are the radiation of interest in the spectral range of $3500-3800 \mathrm{~cm}^{-1}$ and the sharp features around $5500 \mathrm{~cm}^{-1}(1.8 \mu \mathrm{m})$ which have been identified as atomic oxygen and nitrogen lines in previous studies performed at the Air Force Geophysics Laboratory. ${ }^{13}$

Figure 8 displays a calibrated version of the spectrum of Figure 7 over the spectral range of $3100-3800 \mathrm{~cm}^{-1}(3.23-2.63 \mu \mathrm{m})$. Also shown for comparison is a computer generated NO first overtone spectrum. The generated spectrum is calculated using the latest spectroscopic constants of NO and includes contributions from both total angular momentum states. The shapes of all vibrational/rotation transitions in the synthetic spectrum are broadened by a sinc slit function appropriate to the interferometer used in the experiments. The synthesized spectrum

13. Murphy, R.E., Fairbarn, A. R., Rogers, J. W., and Hart, A. M. (1975) Near IR Nuclear Spectra: Interpretation by Recent Laboratory Results, presented at the Fourth Strategic Space Symposium, Monterey, CA. 
was chosen to have a Boltzmann vibrational distribution corresponding to a vibrational temperature of $5000^{\circ} \mathrm{K}$ and a rotational temperature of $300^{\circ} \mathrm{K}$; no attempt has been made to fit the two spectra. It is seen that the structure of the experimental spectrum taken in room air lines up very well with the predicted NO spectrum, leading to the conclusion that $\mathrm{NO}$ is the dominant radiator in the $2.6-3.2 \mathrm{um}$ region under these conditions. Again fluorescence arising from vibrational excited NO up to level $\mathrm{v}=6$ is observed.

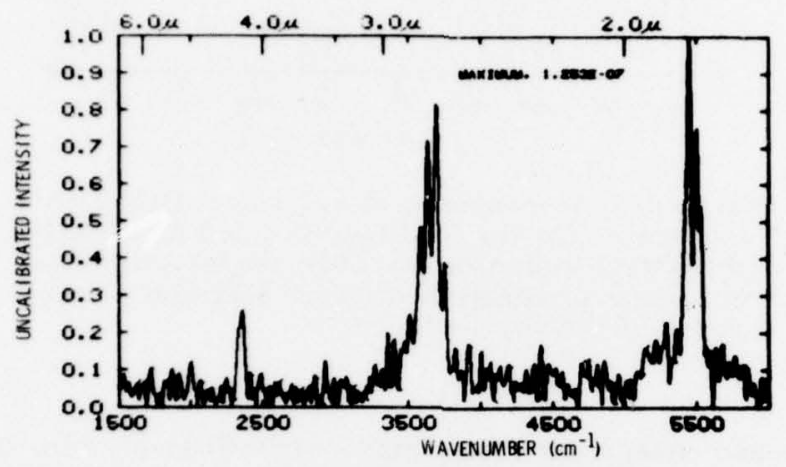

Figure 7. Uncalibrated Fluorescence Observed With $\mathrm{PbS}$ Detector at Beam Termination From Filtered Room Air Under Standard Slow-Flow Conditions. Resolution is $20 \mathrm{~cm}^{-1}$. Radiation observed is from $\mathrm{CO}_{2}\left(\nu_{3}\right)$ at $4.3 \mathrm{um}, \mathrm{NO}(\Delta \mathrm{v}=2)$ at $2.7 \mathrm{um}$ and atomic $\mathrm{O}$ and $\mathrm{N}$ at $1.8 \mathrm{\mu m}$

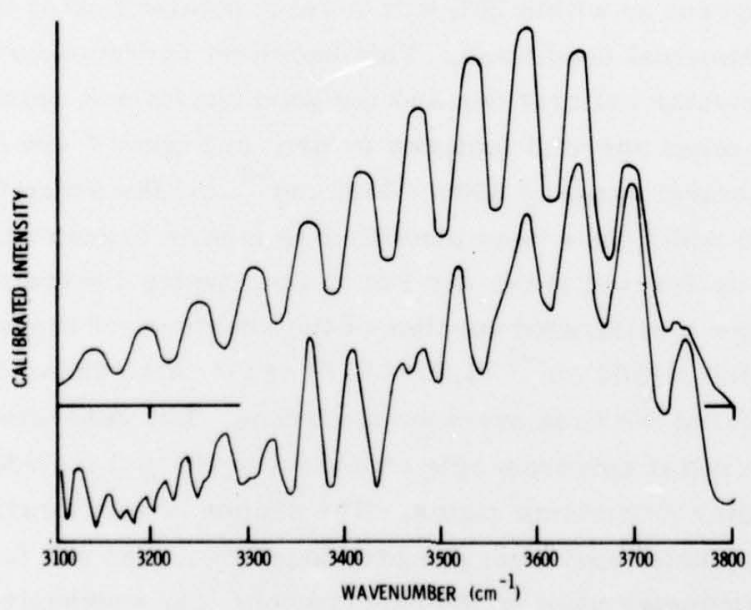

Figure 8. Comparison of SWIR Fluorescence with Synthetic Spectrum of NO Lower trace: Expansionof $3100-3800 \mathrm{~cm}^{-1}$ Region of Figure 7. Calibrated maximum intensity is $1.5 \times 10^{-10} \mathrm{~W} / \mathrm{cm}^{2}-\mathrm{str}-\mathrm{cm}^{-1}$. Upper trace: Synthesized spectrum of NO overtone radiation (see text for details) 
When the spectral resolution is increased to $10 \mathrm{~cm}^{-1}$ reproducible features not attributable to NO appear, as is shown in Figure 9. Although the noise level of the $10 \mathrm{~cm}^{-1}$ calibrated spectrum is greater than the $20 \mathrm{~cm}^{-1}$ spectrum of Figure 8 , the features indicated by arrows are reproducible both as a function of time and from run to run. The expected spectral shapes of the $\mathrm{N}_{2} \mathrm{O}\left(02^{\circ} 1 \rightarrow 00^{\circ} 0\right)$ and $\left(10^{\circ} 1 \rightarrow 00^{\circ} 0\right)$ combination bands as well as the $\mathrm{CO}_{2}\left(02^{\circ} 1 \rightarrow 00^{\circ} 0\right)$ and $\left(10^{\circ} 1 \rightarrow 00^{\circ} 0\right)$ combination bands are also shown in Figure 9. It is clear that $\mathrm{CO}_{2}$ radiation does not occur in any significant amount in this spectral region. The $\mathrm{N}_{2} \mathrm{O}$ combination band at $3480 \mathrm{~cm}^{-1}$ does seem to match the frequency, if not the shape, of some of the unidentified spectral features. (This band is predicted to be the strongest in this spectral region ${ }^{5}$ for $\mathrm{N}_{2} \mathrm{O}$ in vibrational equilibrium at room temperature. Nonetheless, even if the $3480 \mathrm{~cm}^{-1}$ features are attributed to $\mathrm{N}_{2} \mathrm{O}$, other strong features remain unexplained.

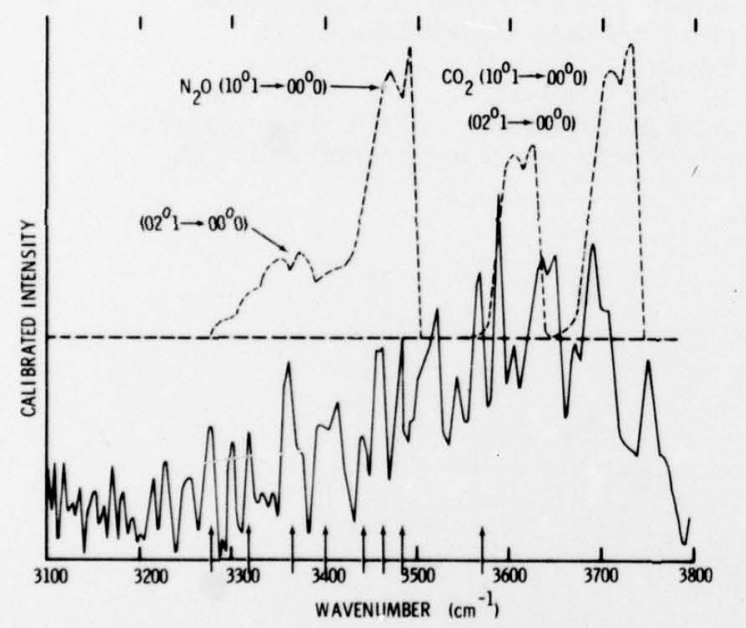

Figure 9. Spectrum of Filtered Room Air with Estimated $\mathrm{CO}_{2}$ and $\mathrm{N}_{2} \mathrm{O}$ Bands Shown for Comparison. Lower trace: spectrum of filtered room air is as in Figures 6 and 7 at $10 \mathrm{~cm}^{-1}$ resolution. Maximum calibrated intensity is $1.8 \times 10^{-10}$ $\mathrm{W} / \mathrm{cm}^{2}-\mathrm{str}-\mathrm{cm}^{-1}$. Upper trace: estimated $\mathrm{N}_{2} \mathrm{O}$ and $\mathrm{CO}_{2}$ combination band shapes and relative intensities. Arrows along bottom axis indicate reproducible features not due to NO

The SWIR spectrum of a slow-flow run taken with a $80 \% \mathrm{~N}_{2} / 20 \% \mathrm{O}_{2}$ mixture is shown in Figure 10. The data, shown with $10 \mathrm{~cm}^{-1}$ resolution, is taken at the time of beam termination. Again, as for the filtered room air cases, NO is the dominant radiator in the spectral region shown. The lack of significant $\mathrm{CO}_{2}$ radiation in this spectral region is demonstrated in Figure 11 which provides a comparison between the spectra recorded in filtered room air and an $80 \% \mathrm{~N}_{2} / 20 \% \mathrm{O}_{2}$ mixture where no $\mathrm{CO}_{2}$ should be present. It can be seen that there are no observable differences between the two scans with the exception that the laboratory-air case appears to have a somewhat greater spectral resolution. Interestingly enough even the features 
attributed to noise appear to line up: the unexplained spectral features of the air runs are also present in the $\mathrm{N}_{2} / \mathrm{O}_{2}$ experiments.

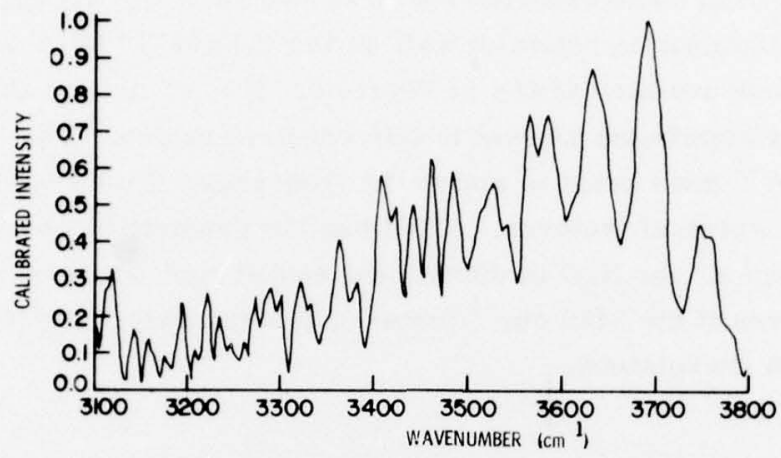

Figure 10. SWIR Fluorescence From $80 \% \mathrm{~N}_{2} / 20 \% \mathrm{O}_{2}$ Mixtures at 100 Torr Pressure Under Slow-Flow Conditions. Resolution is $10 \mathrm{~cm}^{-1}$. Maximum intensity is $3.6 \times 10^{-10} \mathrm{~W} / \mathrm{cm}^{2}-\mathrm{str}-\mathrm{cm}^{-1}$. Increase in NO radiation is in agreement with MWIR observations NO fluorescence was decreased in the presence of $\mathrm{CO}_{2}$

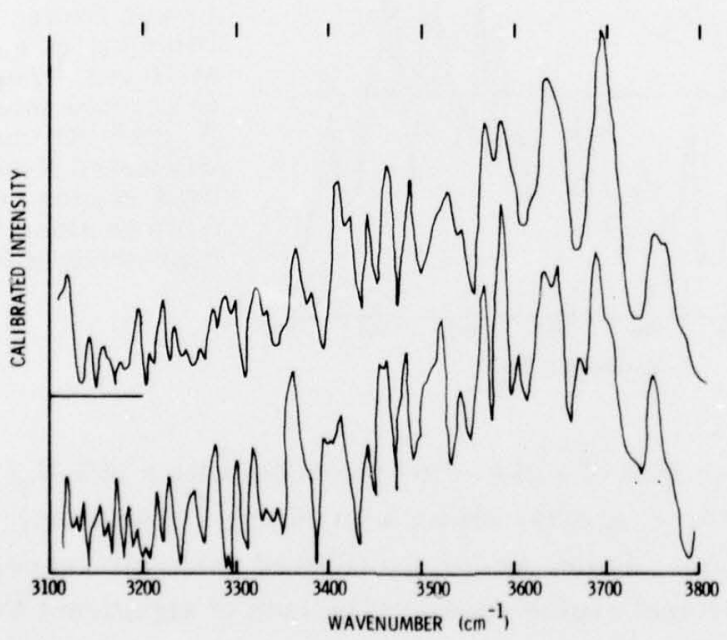

Figure 11. Comparison of $\mathrm{N}_{2} / \mathrm{O}_{2}$ and Room Air Spectra Taken Under Similar Conditions. Resolution is $10 \mathrm{~cm}^{-1}$. Lower trace: room air fluorescence (Figure 9). Upper trace: $\mathrm{N}_{2} / \mathrm{O}_{2}$ fluorescence (Figure 10) 
Measurements taken under faster flow conditions and for much shorter residence times yield similar spectra. In these cases only runs using the $\mathrm{PbS}$ detector were possible due to decreased signal intensity, but the unidentified features remained. If these features were atrributable to a build up of beam created species, such as $\mathrm{N}_{2} \mathrm{O}$, their relative intensity should have been greatly diminished because of the decreased residence time. In fact, $\mathrm{N}_{2} \mathrm{O}\left(\nu_{3}\right)$ radiation at $4.5 \mu \mathrm{m}$ was no longer observed for these runs (with the $\mathrm{PbS}$ detector). Radiation arising from $\mathrm{NO} \Delta \mathrm{v}=2$ transitions is still the dominant radiation source at $2.7 \mu \mathrm{m}$ under these conditions, and the NO vibrational distribution appears to be very similar to that of the higher pressure runs.

The experiments performed using trace concentrations of oxygen mixed with nitrogen provided slightly more signal in the MWIR region. No evidence of $\mathrm{N}_{2} \mathrm{O}$ fluorescence at $4.5 \mu \mathrm{m}$ is observed in these spectra. The observed vibrational distribution of $\mathrm{NO}$ is not greatly different from that of the $80 \% \mathrm{~N}_{2} / 20 \% \mathrm{O}_{2}$ mixture data of Figure 2. In these runs the nitrogen pressure was varied from $25-115$ Torr and the oxygen pressure, set to achieve maximum intensity, was varied from $0.2-0.75$ Torr. No variation in the observed NO excited vibrational distribution was noted over this range of conditions. The measured NO fluorescence decay rate was in good agreement with previous observations. ${ }^{11}$ A more systematic study of this type might permit the measurement of individual vibrational level decay rates of $\mathrm{NO}$ by $\mathrm{N}_{2}$ and $\mathrm{O}_{2}$.

When the PbS, SWIR sensitive detector was used, the observed NO spectral intensity increased by a factor of 2 over the air cases. The unidentified features noted previously all increased by an even greater amount, about a factor of 4 , and are the most prominent spectral features, as shown in Figure 12. The displayed spectrum is from a 100 -Torr $\mathrm{N}_{2}, 0.03$-Torr $\mathrm{O}_{2}$ slow-flow run, and corresponds to the time of beam termination. The NO vibrational bands are greatly obscured by the sharp spiked features that have widths equal to the experimental resolution. Since unresolved vibration-rotational bands would have spectral widths much greater than this, the features were suspected to be either due to atomic lines or individual rotational lines of a molecular vibrational band.

Under certain conditions the unidentified spectral features were found to persist long after NO fluorescence had decayed. Figure 13 shows a spectrum taken in the same experiment as Figure 12, but at a time corresponding to $3.4 \mathrm{msec}$ after beam termination. Some residual NO radiation from the slowest decaying observable level $(\mathrm{v}=2)$ might be present between 3650 and $3770 \mathrm{~cm}^{-1}$. Most striking, however, is the appearance of the unidentified spectral features. Indeed some weaker features attributed to noise in the other runs are observed to be reproducible with time under these conditions. Note that the relative intensity of the lines appears unchanged from early time observations, see comparison of Figures 12 and 13 . These long 
time observations provided a much clearer picture of the unidentified radiator. Specifically the strong feature at $\sim 3560 \mathrm{~cm}^{-1}$ was noted to agree well with the fre quency of the $Q$ branch of the $O H(v=1 \rightarrow 0)$ transition. The free radical $O H$ was considered a likely radiation source inasmuch as water was introduced into the system with the room air and could have a long residence time on the chamber surfaces for typical system pumping rates.

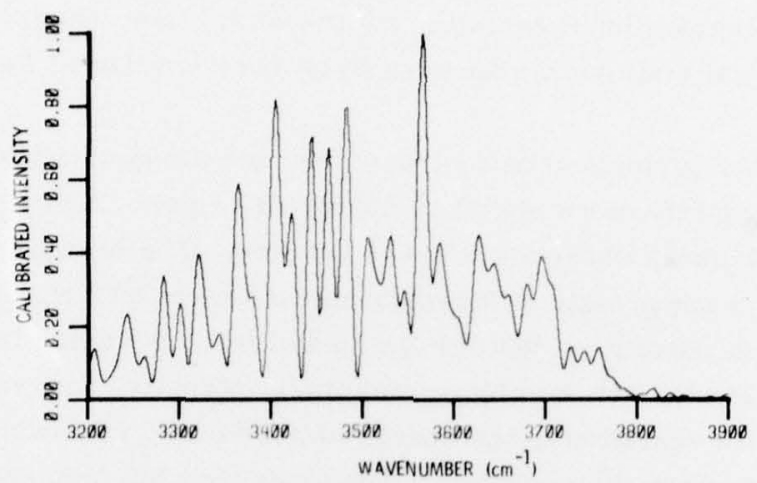

Figure 12. SWIR Fluorescence From a Trace Oxygen Run Under Slow-Flow Conditions. The $\mathrm{N}_{2}$ pressure is 100 Torr. $\mathrm{O}_{2}$ pressure is 0.03 Torr. Resolution is $10 \mathrm{~cm}^{-1}$ and maximum intensity is $6.1 \times 10^{-10} \mathrm{~W} / \mathrm{cm}^{2}-\mathrm{str}-\mathrm{cm}^{-1}$ at beam termination. The NO radiation is no longer the dominant spectral radiation

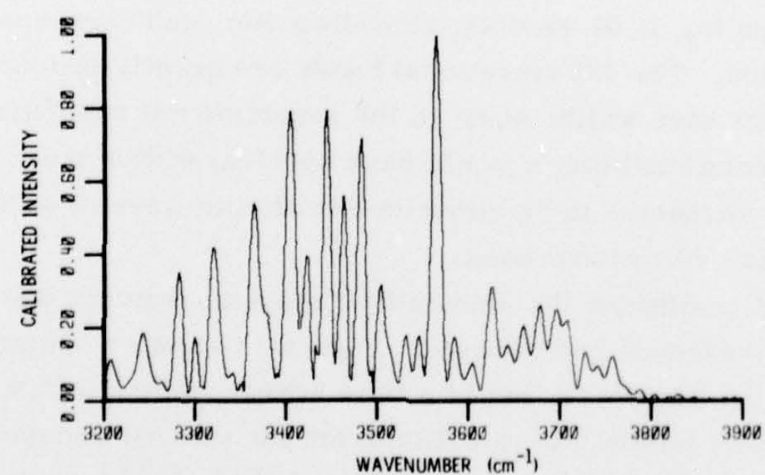

Figure 13. SWIR Fluorescence $3.5 \mathrm{msec}$ After Beam Termination for Run of Figure 12. Maximum intensity is $1.9 \times 10^{-10} \mathrm{~W} / \mathrm{cm}^{2}-\mathrm{str}-\mathrm{cm}^{-1}$. The NO overtone radiation has virtually disappeared, isolating the spectral lines of interest 
In order to verify the tentative assignment, a synthetic spectrum of the $\mathrm{OH}$ molecule was generated. The $\mathrm{OH}$ free radical has an inverted ${ }^{2} \pi$ ground electronic state with strong coupling between spin and angular momentum giving rise to two total angular momentum manifolds of states $\Omega=1 / 2$ and $3 / 2$. Transitions between similar states within these manifolds are not degenerate and should be easily observable. Coupling of rotation to the total angular momentum is a complex function of the rotational and vibrational energy and a vibrating rotor-anharmonic oscillator model of the spectrum is not sufficient. Detailed predictions of the OH spectral line positions and strengths have been performed by Mies ${ }^{14}$ and shown to be in good agreement with experimental spectra. Mies' calculated frequencies and Einstein coefficients were used to generate a synthetic OH spectrum using a sinc slit function and assuming a $300^{\circ} \mathrm{K}$ rotational temperature. A comparison between this synthesized spectrum and the long time spectrum of Figure 13 is presented in Figure 14.

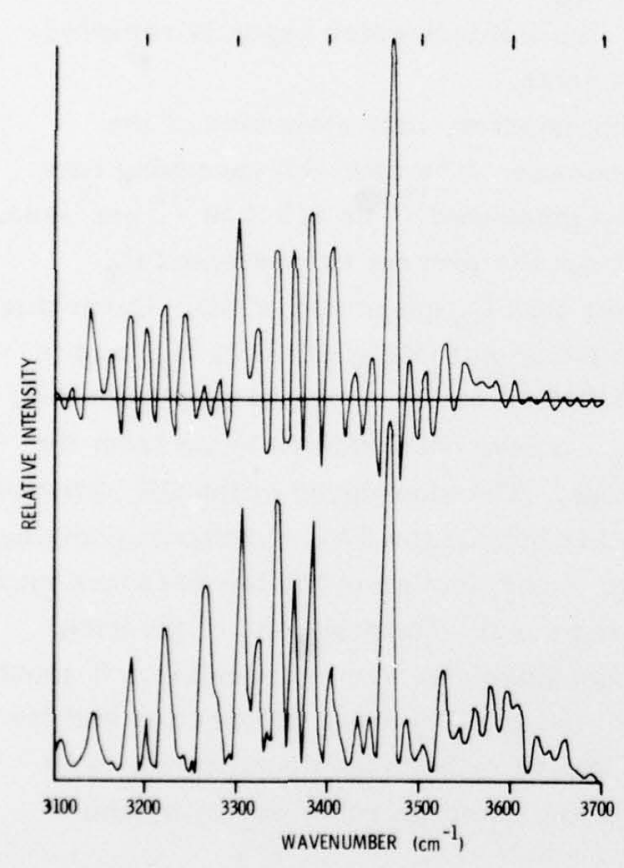

Figure 14. Comparison of Synthetic Spectrum of $\mathrm{OH}$ With Spectral Features of Figure 13. All significant features (except $3270 \mathrm{~cm}^{-1}$ line) are matched by $\mathrm{OH}$ predictions

(Note that the synthetic spectrum exhibits negative values of intensity. This is a result of convoluting the predicted $\mathrm{OH}$ spectrum over a sinc slit function which displays prominent negative sidelobes. This effect is an artifact of the Fourier

14. Mies, F. H. (1974) Calculated vibrational transition probabilities of $\mathrm{OH}\left(\mathrm{X}^{2} \pi\right)$, J. Molec. Spectrosc. 53:150. 
transform.) It can be seen that the prominent spectral features match OH vibration/ rotation lines. In addition, excellent agreement occurs between the spectral positions of nearly all of the weaker features and $\mathrm{OH}$ lines arising from high $\mathrm{J}$ levels and the weaker, $\Omega_{1 / 2}$ transitions. Note that in the synthetic spectrum, the relative populations of the two spin states and the rotational levels are assumed to be in the thermal equilibrium with the gas kinetic temperature. The observed relative $\mathrm{OH}$ vibrational populations can be readily determined from the measured $Q$ branch intensities and it has found that the relative populations of $\mathrm{OH} v=2$ and $v=1$ are nearly equal at beam termination $\left(n_{2} / n_{1}=0.8\right)$ for all the runs in which they could be observed (including trace oxygen, and fast and slow-flow cylinder gas and room air runs.)

Upon backchecking it was found that the $\mathrm{OH}$ spectrum was not observed in early runs made using cylinder gases prior to that admission of room air into the chamber. Thus it appears that once water vapor was admitted it strongly adhered to the chamber surfaces and ultimately gave rise to the $\mathrm{OH}$ fundamental band radiation even in "dry" air mixtures. Additionally, not all the ambient water vapor is removed by the trap in the filtered room air measurements.

Due to the slow time response of the $\mathrm{PbS}$ detector, only estimates of the quenching rates of $\mathrm{OH}$ by $\mathrm{O}_{2}$ and $\mathrm{N}_{2}$ could be made. The total $\mathrm{OH}$ quenching rate constant by an air mixture of $\mathrm{N}_{2} / \mathrm{O}_{2}$ has been measured ${ }^{15}$ as $1.5 \times 10^{-14} \mathrm{~cm}^{3} / \mathrm{sec}$, dominated by $\mathrm{O}_{2}$ quenching. Observations from the present work support $\mathrm{O}_{2}$ quenching of $\mathrm{OH}$ as faster than $\mathrm{N}_{2}$, but slower than $\mathrm{O}_{2}$ quenching of NO. Quenching of $\mathrm{OH}$ by $\mathrm{N}_{2}$ appears to be significantly faster than quenching of $\mathrm{NO}$ by $\mathrm{N}_{2}$, and is estimated to have a rate constant of order $1.5 \times 10^{-15} \mathrm{~cm}^{3} / \mathrm{sec}$ which is approximately $10 \%$ of the rate constant for quenching by $\mathrm{O}_{2}$. These observations arise from the analysis of the low pressure trace oxygen runs. The slow decay of the OH radiation in Figures 12 and 13 ( $\mathrm{P}=100$ Torr) can possibly be explained by vibrational pumping from $\mathrm{N}_{2}(\mathrm{v} \geq 2)$ which would not make as large a contribution in the low pressure runs (a more detailed investigation is obviously required). Observations of the decay $\mathrm{OH}(\mathrm{v}=2)$ are limited and estimates of the quenching rates are not possible. It should be emphasized that the present study was not designed to study $\mathrm{OH}$ kinetics and the above observations must be considered qualitative rather than quantitative. For example the possible chemical destruction of $\mathrm{OH}$, through reactions with beam produced species, has not been considered.

15. Murphy, R.E. (1971) Infrared emission of $\mathrm{OH}$ in the fundamental and first overtone bands, J. Chem. Phys. 54:4852. 


\section{SUMMARY AND CONCLUSIONS}

In summary, an examination of the infrared fluorescence arising from both electron irradiated air and nitrogen/oxygen mixtures has been provided. The study was limited to the spectral range of $1600-6700 \mathrm{~cm}^{-1}(1.5-6 \mu \mathrm{m})$ by detector response/system background considerations. The dominant spectral features observed included fluorescence from: (a) previously identified atomic nitrogen and oxygen transitions occurring near $5500 \mathrm{~cm}^{-1}$, (b) the fundamental and first overtone vibrational bands of NO, and (c) the fundamental bands of the $\nu_{3}$ modes of $\mathrm{CO}_{2}$ and $\mathrm{N}_{2} \mathrm{O}$. The $\mathrm{CO}_{2}$ fluorescence was of course not observed in irradiated mixtures of bottled $\mathrm{N}_{2} / \mathrm{O}_{2}$, but rather only when room air was admitted into the test chamber. Lastly a persistent contaminant radiator, observed in the majority of the measurements, has been identified as OH.

The basic conclusion of this report is that, for the conditions considered, there is no evidence of $\mathrm{CO}_{2}$ combination band radiation occurring at or near $2.7 \mu \mathrm{m}$ in electron irradiated air. This is true even though non-equilibrium concentrations of $\mathrm{CO}_{2}\left(\nu_{3}\right)$ were observed. Indeed, in the $2.7 \mu \mathrm{m}$ region, there are no significant differences between the spectra observed in air and in $80 \% \mathrm{~N}_{2} / 20 \% \mathrm{O}_{2}$ mixtures. These results are specific to pressures of 10 - 100 Torr and need not be representative of upper atmospheric phenomena. This is because the level of $\mathrm{CO}_{2}$ combination band fluorescence is proportional to the populations of the $\mathrm{CO}_{2} \nu_{1}$ and $\nu_{2}$ modes which in turn can be controlled by the rate of vibrational quenching collisions which is altitude dependent.

A number of interesting side features that could be studied in more detail have been observed in this data. These include: (a) the observation of OH fluorescence and decay which might be utilized to ascertain fundamental quenching rate constants for vibrationally excited $\mathrm{OH}$, (b) NO fluorescence data sufficiently resolved to allow determination of vibrational level dependent quenching rate constants and relative fundamental to first overtone band Einstein coefficients, and (c) the possibility of using trace quantities of $\mathrm{CO}_{2}$ to determine relative populations of $\mathrm{N}_{2} \mathrm{O}$ and vibrationally excited $\mathrm{N}_{2}$. 


\section{References}

1. Proceedings of the HAES Infrared Data Review, 13-15 June 1977, Falmouth, MA, AFGL Report OP-TM-05.

2. Proceedings of the HAES Infrared Data Review, 13-15 June 1977, AFGL Report OP-TM-05, pp 327-341, presented by H. Mitcinell.

3. O'Neil, R.R., unpublished results.

4. Murphy, R.E., unpublished results.

5. McClatchey, R. A., Benedict, W.S., Clough, S. A., Burch, D. E., Calfee, R. F., Fox, K., Rothman, L.S., and Garing, J.S. (1973) Atmospheric Absorption Line Parameters Compilation, AFCRL-TR-73-0096.

6. Murphy, R.E., Cook, F.H., Caledonia, G. E., and Green, B. D. (1977) Infrared Fluorescence of Electron Irradiated $\mathrm{CO}_{2}$ in the Presence of $\mathrm{N}_{2}$, A $\overline{\mathrm{r} \text { and }}$ He, AFGL-TR-77-0205.

7. Cook, F.H., and Murphy, R. E. (1976) A Synchronous Signal Processing Technique for Repetitive Arbitrary Waveforms, AFCRL-TR-76-0035.

8. Murphy, R. E., Cook, F.H., and Sakai, H. (1975) Time resolved Fourier spectroscopy, J. Opt. Soc. Amer. 65:600.

9. O'Neil, R. , and Davidson, G. (1968) The Fluorescence of Air and Nitrogen Excited by Energetic Electrons, American Science and Engineering, Inc. report ASE-1602 (AFCRL-67-0277).

10. Billingsley, II, F.P. (1976) Calculated vibration rctation intensities for NO(X $\left.{ }^{2} \mathrm{II}\right)$, J. Molec. Spectrosc. $61: 53$.

11. Murphy, R. E., Lee, E. T. P., and Hart, A. M. (1975) Quenching of vibrationally excited nitric oxide by molecular oxygen and nitrogen, J.Chem. Phys. $63: 2919$.

12. Yardley, J.T. (1968) Vibration-to-vibration energy transfer in gas mixtures containing nitrous oxide, J. Chem. Phys. 49:2816.

13. Murphy, R.E., Fairbarn, A.R., Rogers, J. W., and Hart, A. M. (1975) Near IR Nuclear Spectra: Interpretation by Recent Laboratory Results, presented at the Fourth Strategic Space Symposium, Monterey, CA.

14. Mies, F.H. (1974) Calculated vibrational transition probabilities of $\mathrm{OH}\left(\mathrm{X}^{2} \mathrm{II}\right)$, J. Molec. Spectrosc. $533: 150$.

15. Murphy, R.E. (1971) Infrared emission of OH in the fundamental and first overtone bands, J. Chem. Phys. 54:4852. 
DNA DISTRIBUTION LIST

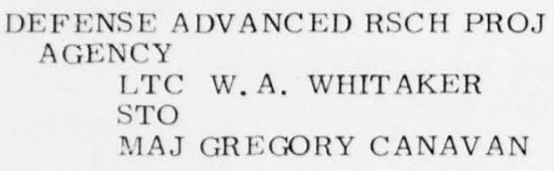

DIR OF DEFENSE RSCH \& ENGINEER ING

DEPARTMENT OF DEFENSE DD/S\&SS DANIEL BROCKWAY DD/S\&SS(OS)

FIELD COMMAND

DEFENSE NUCLEAR AGENCY FCRP

LIVER MORE DIVISION FLD COMMAND DNA FCPRL

\section{AT MOS PHERIC SCIENCES}

LABORATORY DRSEL-BL-SY-A F. NILES H. BALLARD

HARRY DIAMOND LABORATORIES DRXDO-NP F. H. WIMINET?

U.S. ARMY NUCLEAR AGENCY MONA -WE

BMD ADVANCED TECH CTR ATC $-O$, W. DAVIES ATC $-\mathrm{T}, \mathrm{M}$. CAPPS

DEP. CHIEF OF STAFF FOR RSCH DEV \& ACQ

DEPARTMENT OF THE ARMY

MCB DIVISION

DAMA - CSZ -C
U.S. ARMY BALLISTIC RESEARCH LABS

DRXBR-AM, G. KELLER DRXR D-BSP, J. HEIMERL JOHN MESTER

TEC H LIBR ARY

US ARMY ELECTRONICS COMMAND INST FOR EXPL RSCH DRSEL

STANLEY KRONENBERGER WEAPONS EFFECTS SECTION

US ARMY FOREIGN SCIENCE \& TECH CTR ROBERT JONES

US AR MY RESEARCH OFFICE ROBERT MACE

NAVAL OCEANS SYSTEMS CENTER CODE 2200 ILAN ROT HMULLER CODE 2200 HERBERT HUGHES CODE 2200 JURGEN RICHTER CODE 2200.WILLIAM MOLER CODE 2200 RICHARD PAPPERT

NAVAL RESEARCH LABORATORY CODE 7712 DOUGLAS P. MCNUTT CODE 7701 JACK D. BROWN CODE 2600 TECH LIB CODE 7237 CHARLES Y. JOHNSON CODE 7700 TIMOTHY P. COFFEY CODE 7709 WAHAB ALI CODE 7750 DARRELL F. STROBEL CODE 7750 PAUL OULUENNE CODE $7750 \mathrm{~J}$. FEDDER CODE $7750 \mathrm{~S}$. OSSAKON CODE $7750 \mathrm{~J}$. DAVIS

NAVAL SURFACE WEA PONS CENTER CODE WA501 NAVY NUC PRGMS OFF TECHNICAL LIERARY

SUPERINTENDENT

NAVAL POST GRADUATE SCHOOL TECH REPORTS LIBRARIAN

NAVAL ELECTRONICS SYSTEMS COMMAND PME 117

NAVAL INTELLIGENCE SUPPORT CNTR DOC UMENT CONTROL 
AF GEOPHYSICS LABORATORY, AFCS LKB KENNETHS. W. CHAMPION OPR ALVA T. STAIR, Jr OPR -1 J. ULWICK OPR - 1 R. MURPHY OPR -1 J. KENNEALY PHG J.C. MCCLAY LKD ROCCO NARCIS LKO R. HUFF MAN

AF WEAPONS LABORATORY AFSC SUL MAJ GARRY GANONG, DYM

\section{COMMANDER}

ASD

ASD-YH-EX LTC ROBERT LEVERETTE

SAMSO/AW SZJ MAJ LAWRENCE DOAN AWN

AFTAC TECH LIBRARY TD

HQ

AIR FORCE SYSTEMS COMMAND

DLS

TECH LIBRARY

DLCAW

DLTW

DLXP

SDR

HQ USAF/RD

RDQ

ROME AIR DEVELOPMENT CTR J.J. SIMONS OCSC

DIVISION OF MILIT ARY APPLICATION DOC CON

LOS ALAMOS SCIENTIFIC LABORATORY

DOC CON FOR R. A. JEFFERIES DOC CON FOR C.R. MEHL ORG 5230

DOC CON FOR H.V. ARGO DOC CON FOR M. TIERNEY

DOC CON FOR $\mathrm{J}-10$

ROBERT BROWNLEE

DOC CON FOR WILLIAM MAIER

DOC CON FOR JOHN ZINNY

DOC CON FOR REFERENCE LIBRARY ANN BEYER
SANDIA LABORATORIES -

LIVER MORE, CA

DOC CONTROL FOR

THOMAS COOK ORG 8000

SANDIA LABORATORIES -

A LBUQUERQUE, NM

DOC CON FOR W. D. BROWN ORG 1353

DOC CON FOR L. ANDERSON ORG 1247

DOC CON FOR MORGAN KRAMMA ORG 5720

DOC CON FOR FRANK HUDSON ORG 1722

DOC CON FOR SANDIA REPTS

COLL. ORG 3422-1

AR GONNE NATIONAL LABORATORY DOC CON FOR A.C. WAHL DOC CON FOR DAVID H. GREEN DOC CON FOR LIB SVCS RPTS SEC

DOC CON FOR S. GABELNICK DOC CON FOR GERALD T. REEDY

UNIVERSITY OF CALIFOR NIA

W. H. DUEWER GEN L -404

JULIUS CHANG L -71

G. R. HAUGEN L-404

D. J. WUERBLES L-142

US ENERGY RSCH \& DEV ADMIN DOC CON FOR CLASS TECH LIB

DEPARTMENT OF TRANSPORTATION SAMUEL C. CORONITI

NASA

GODDAR D SPACE FLIGHT CENTER

A.C. AIKEN

A. TEMPKIN

J. BAUER

TECHNICAL LIBRARY

J. SIRY

NASA

A. GESSOW

D. P. CAUFF MAN

LTC D. R. HALLENBECK CODE SG

R. FELLOWS

A. SCHARDT

M. TEPPER

NASA

LANGLEY RSCH CENTER

CHARLES SCHEXNAY DER MS - 16A 
NASA

AMES RSCH CENTER

N-254-4 WALTER L. STARR

N-254-4 R. WHITTEN UNCL ONLY $\mathrm{N}-254$-4 ILIA G. POPPOFF

N-254-3 NEIL H. FARLOW

NASA

GEORCE C. MARSHALL SPACE

FLIGHT CENTER

C.R. BALCHER

N. H. STONE

CODE ES22 JOHN WATTA

W. T. ROBERTS

R. D. HUDSON

R. CHAPPELL

ALBANY METALLURGY RSCH CTR ELEANOR ARSHIRE

CENTRAL INTELLIGENCE AGENCY NES/OSI - 2 G48 HQS

DEPARTMENT OF COMMERCE

SEC OFFICER FOR

JAMES DEVOR

SEC OFFICER FOR

ST ANLEY ABRAMOWITZ

SEC OFFICER FOR

J , COOPER

SEC OFFICER FOR GEORGE A. SINNATT

SEC OFFICER FOR K. KESSLER

SEC OFFICER FOR M. KRAUSS

SEC OFFICER FOR LEWIS $\mathrm{H}$, GEV ANT MAN SEC OFFICER YOR JAMES DEVCE

NATIONAL OCEANIC \& ATMOSPHERIC ADMIN GEORGE C. REID AERONOMY LAB UNCL ONLY ELDON FERGUSON FRED FEHSENFELD

A.ERO-CHEM RSCH

LABORATORIES INC.

A. FONTIJN

H. PERGAMENT

AERODYNE RESEARCH, INC . F. BIEN

M. CAMAC
AERONOMY COR PORATION

S. A. BOWHILL

AEROSPACE COR PORATION

N. COHEN

HARRIS MAYER

SIDNEY W. KASH

T. WIDHOPH

R.J. MCNEAL

R. GROVE

IRVING M. GARFUNKEL

THOMAS D. TAYLOR

V. JOSEPHSON

JULIAN REINHEIMER

R. D. RAWCLIFFE

AVCO-EVERETT RSCH

LABORATORY, INC.

TECHNICAL LIBRARY

GEOR GE SUT TON

C.W. VON ROSENBERG, JT

BATTELLE MEMORIAL INSTITUTE

DONALD J. HAMMAN

STOIAC

RICHARD K. THATCHER

THE TRUSTEES OF BOSTON COLLEGE CHAIR MAN DEPT OF CHEM

BROWN ENGINEERING COMPANY, INC. N. PASSINO

RONALD PATRICK

CALIFORNIA AT RIVERSIDE, UNIV OF ALAN C. LLOYD

JAMES N. PITTS, JR.

CALIFORNIA AT SAN DIEGO, UNIV OF S. C. LIN

CALIFORNIA INSTIT UTE OF TECHNOLOGY

JOSEPH·AJELLO

CALIFORNIA, UNIVERSITY OF SEC OFFICER FOR HAROLD JOHNSTON

SEC OFFICER FOR F. MOZER

SEC OFFICER FOR DEPT OF CHEM W. MILLER

CALIFORNIA, STATE OF LEO ZAFONTE 


\section{CALSPAN CORPORATION \\ C. E. TREANOR \\ G. C. VALLEY \\ M. G. DUNN \\ W. WURSTER}

COLORADO, UNIVERSITY OF

A. PHELPS JILA

JEFFREY B. PEARCE LASP

C. BEATY JILA

C. LINEBERGER JILA

CHARLES A. BARTH LASP

COLUMBIA UNIVERSITY, THE

TRUSTEES OF

RICHAR D ZARE

SEC OFFICER H. M. FOLEY

\section{CONCORD SCIENCES}

EMMETT SUTTON

DENVER, UNIVERSITY OF

SEC OFFICER FOR VAN ZYL SEC OFFICER FOR DAVID MURCRAY

GENERAL ELECTRIC COMPANY TEMPO CENTER FOR

ADVANCED STUDIES

DASAIC

WARREN S. KNAPP

TIM STEPHEN

DON CHANDLER

B. CAMBILL

GENERAL ELECTRIC COMPANY SPACE DIVISION -

VALLEY FORGE SPACE CTR

M. H. BORTNER SPACE SCIENCE LAB

J. BURNS

F. ALYEA

P. ZAVITSANDS

R. H. EDSALL

T. BAURER

GENERAL RSCH CORPORATION JOHN ISE, Jr.

GEOPHYSICAL INSTITUTE

D. J. HENDERSON

J.S. WAGNER PHYSICS DEPT

B.J. WATKINS

T. N. DAVIS

R. PRATHASARATHY

NEAL BROWN

INSTITUTE FOR DEFENSE ANALYSIS

HANS WOLFHARD

ER NEST BAUER
LOWELL, UNIVERSITY OF

G. T. BEST

LOCKHEED MISSILES AND SPACE COMPANY

JOHN KUMER DEPT 52-54

JOHN B. CLADIS DEPT 52-12

BILLY M. MCCORMAC DEPT $52-54$

TOM JAMES DEPT 52-54

J. B. REAGAN DEPT 52-12

MARTIN WALT DEPT 52-10

RICHARD G. JOHNSON

DEPT 52-12

ROBERT D. SEARS DEPT 52-14

MISSION RESEARCH CORPORATION
D. ARCHER
P. FISCHER
M. SCHEIBE
D. SAPPENFIELD
D. SOWLE

MINNESOTA, UNIVERSITY OF J.R. WINKLER UNCLAS ONLY

PHOTOMETRIC, INC. IRVING L. KOFSKY

PHYSICAL DYNAMICS INC. JOSEPH B. WORKMAN

A. THOMPSON

PHYSICAL SCIENCES, INC. KURT WRAY

R. L. TAYLOR

G. CALEDONIA

PHYSICS INTERNATIONAL COMPANY DOC CON FOR TECH LIB

PITTSBURGH, UNIVERSITY OF WADE L. FITE

MANFRED A. BIONDI

FREDERICK KAUF MAN EDWARD GERJUOY

PRINCETON UNIV. THE TRUSTEES OF ARNOLD J. KELLY

$R \&$ D ASSOCIATES - CALIFORNIA

RICHAR D LATTER

R. G. LINDGREN

BRYAN GABBARD

H. A. DRY

ROBERT E. LELEVIER

R. P. TURCO

ALBERT L, LATTER

FORREST GILMORE

D. DEE 
R \& D ASSOCIATES - VIRGINIA HERBERT J. MITCHELL J.W. ROSENGREN

\section{RAND COR PORATION CULLEN CRAIN}

SCIENCE APPLICATIONS, INC. DANIEL A. HAMLIN

DAVID SACHS

SPACE DATA CORPORATION EDWARD ALLEN

ST ANFORD RESEARCH INSTITUTE INTERNATIONAL - CALIFORNIA M. BARON

RAY L. LEADABRAND

WALTER G. CHESTNUT

STANFORD RESEARCH INSTIT UTE

INTERNATIONAL - VIRGINIA

WARREN W. BERNING

CHARLES HULBERT

TECHNOLOGY INTER NAT IONAL COR PORATION

W. P. BOQUIST

UNITED TECHNOLOGIES CORPORATION

H. MICHELS

ROBERT H. BULLIS

UTAH STATE UNIVERSITY DORAN BAKER

KAY BAKER

C. WYATT

D. BURT

VISIDYNE, INC.

HENRY J. SMITH

J.W. CARPENTER

WILLIAM REIDY

T.C. DEGGES

CHARLES HUMPHREY

WAYNE STATE UNIVERSITY

PIETER K. ROL CHEM

ENGRG \& MAT SCI

R. H. KUMMLER

WAYNE STATE UNIVERSITY

DEPT. OF PHYSICS

WALTER KAUPPILA

YALE UNIVERSITY

ENGINEERING DEPARTMENT 